\title{
SYMBOLIC REPRESENTATION HIGHLIGHTED THROUGH PARALLELISM IN A TALE OF TWO CITIES BY CHARLES DICKENS
}

\author{
Su Khine Oo \\ sukhine.oo@outlook.com \\ Yangon University of Foreign Languages, Myanmar
}

\begin{abstract}
The art of writing can be seen when, according to Gauding (2009), "authors use symbols to evoke more than a simple, straightforward, literal meaning". In addition to symbols, the art of poetic writing - Parallelism - emphasizes sounds and ideas in the parallel elements through repetition, development or contrast. However, most research on parallelism was done in poetic or biblical writing. This paper points out symbolic representation highlighted through parallelism in the prose-style novel A Tale of Two Cities by Charles Dickens. It explores how symbols categorized by Pickering and Hoeper (1986) were illustrated through types of parallelism by Lowth (1753), Bullinger (1898), Bulkeley (2001), McCoy (2003), Parry (2007) and Kostenberger and Patterson (2011). The results showed that symbols were represented mainly through semantic parallelism which is used to compare people, things and events using literary devices, and clarification parallelism which conveys additional information about the content. It is hoped that this paper will be useful for teachers teaching Dickens' style found in A Tale of Two Cities with a focus on symbols and parallel structures.
\end{abstract}

Keywords: Clarification parallelism, Dickens, Literary devices, Parallelism, Semantic parallelism, Symbolic representation

\section{INTRODUCTION}

Parallelism refers to the use of similar grammatical structure, sound and meaning in a sentence. It is a literary device which can be found not only in biblical writing but also in daily conversations. Although previous researchers focused on the use of parallelism in biblical writings, research carried out in this paper proved that parallelism can also be found in the novel A Tale of Two Cities by Charles Dickens. The focus of this paper showed that the use of parallelism had effect on illustration of symbolic representation. The results of the research proved that semantic parallelism, clarification parallelism, progression parallelism and repetition parallelism had significant effects on symbolic representation. 
The aim of this paper is to point out illustrating symbolic representation in the novel A Tale of Two Cities by Charles Dickens. The objectives of this paper are: the use of different types of parallelism in

To

investigate

symbolic

representation in the novel.

To explore the way parallelism highlights symbolic representation, and

To identify correlation between symbols and parallelism.

\section{REVIEW OF RELATED LITERATURES}

\subsection{Symbol}

Symbol refers to a person, an object, an event, etc. each of which has a meaning in itself but symbolizes other oblique meanings besides direct meaning. 3 types of symbols defined by Pickering and Hoeper (1986) are known as (1) traditional symbol which is a conventional symbol whose meaning is widely accepted, (2) original symbols which "derive their meaning from the content of the work in which they are used" and (3) private symbol which "restricts the source of its meaning even more than original symbols", and which the writers employ as a product of "their own peculiar and idiosyncratic systems of philosophy or belief".

\subsection{Parallelism}

\subsubsection{Antithetic parallelism}

Bullinger (1898) illustrated that opposite ideas and thoughts are presented to highlight the difference between two things. It can also be used to create ironic effect on the text. The proposition made in one line is reinforced by an idea of contrast in the same line or in another line. Antithetic parallelism is most common in Hebrew poetry which strengthen the idea by contrasting it with another idea.

E.g. "Chateau and hut, stone face and dangling figure, the red stain on the stone floor, and the pure water in the village wellthousands of acres of land- ...."

(Book II, Chapter 16)

\subsubsection{Clarification parallelism}

According to Bulkeley (2001), clarification parallelism can be seen when clarification is given in greater precision. In other words, more information is added to a particular noun or noun phrase for more precision.

E.g. A wonderful corner for echoes, it has been remarked, that corner where the Doctor lived Ever busily winding the golden thread which bound her husband, and her father, and herself, and her old directress and companion, .... 
(Book II, Chapter 21)

\subsubsection{Intensification parallelism}

Bulkeley (2001) stated that intensification parallelism occurs when the information given in the first line is intensified in the other lines. The writer uses words which are stronger in meaning to reinforce the seriousness in his text.

E.g. ... a few of the people fell to dancing Instantly, all the rest fell to dancing, and the courtyard overflowed with the Carmagnole.

(Book III, Chapter 6)

\subsubsection{Progression parallelism}

According to Parry (2007), in progression parallelism, there is an apparent moving forward from one sense or idea to another until, at the pinnacle there is a culmination of thought.

E.g. A figure entering at the door threw a shadow on Madame Defarge which she felt to be a new one. She laid down her knitting, and began to pin her rose in her head-dress, before she looked at the figure.

(Book II, Chapter 16)

\subsubsection{Repetition parallelism}

The same sentence, phrase or word is used again in order to highlight what the writer wants to focus. (Bullinger, 1898)
E.g. "He made shoes, he made shoes, he made shoes."

(Book III, Chapter 1)

\subsubsection{Synonymous parallelism}

Lowth (1753) defines synonymous parallelism as a literary device used to repeat the thought of the first line in the second by using different words or emphasis.

E.g. The bronze face, the shaggy (Syn1) black hair and beard, the coarse ( \pm Syn 1$)$ woollen red cap, ....

(Book II, Chapter 23)

\subsubsection{Synthetic parallelism}

Themes in the second line may explain, emphasize or embellish the first line or the second line may show the results of actions described in the first line. (McCoy, 2003)

E.g. "Hardly any The weather was stormy, and the passage long and rough, (Sy) and I lay on a sofa, almost from shore to shore (Sy)."

(Book II, Chapter 3)

\subsubsection{Semantic parallelism}

According to Kosten-berger and Patterson (2011), semantic parallelism refers to the progression of thought through 
figurative devices like simile and metonymy.

E.g. ... some women held wine to their mouths that they might drink; and what with dropping blood, and what with dropping wine, and what with the stream of sparks struck out of the stone, ....

(Book III, Chapter 2)

\subsection{Previous Research}

Previous researches are of importance in doing further researches as they can help other researchers to think of the gaps and the needs in carrying out related researches. Two previous researches corresponding the current research are "Proverbial Poetry: Its Settings and Syntax" by Hildebrandt (1985), "The Structure of Parallelism in Sa'adi Yusuf's Poetry" by Khader and Kullab (2016), and "Aspects of Political Language and Parallelism" by Ameedi (2017)

In "Proverbial Poetry: Its Settings and Syntax", Hildebrandt (1985) designed a model for capturing the profundities of the syntax of Hebrew poetry. He analyzed Proverbs 10-15, using Whybray's perceptive categories of vocabulary approach, motif approach by Roland (1963) and form approach by Kuntz (1974). Lowth-Gray-Robinson semantic parallelism approach was sub-categorized into synonymous parallelism, emblematic parallelism, antithetic parallelism and synthetic parallelism. $\mathrm{He}$ adopted grammatical parallelism approach which is also known as syntactic parallelism and morphological parallelism to observe "the poetic craftsmanship of the syntax". The results of his research revealed merits and demerits of semantic parallelism approach and grammatical parallelism approach. Those who are familiar with biblical art of writing will benefit from the use of semantic parallelism whereas those who are not well-versed might find it confusing not only because of the use of semantic parallelism but also because of syntax in aesthetic style of writing.

Khader and Kullab (2016), in their research article "The Structure of Parallelism in Sa'adi Yusuf's Poetry", attempted to investigate the presentation of the Sa'adi Yusuf's poetry with focus on its structural forms. They used descriptive analytical approach in analyzing poetic texts. The instrument they used in their analysis was parallelism which was categorized into phonological parallelism, morphological parallelism, lexical parallelism and syntactic parallelism proposed by Alsheikh (1999) and Knony 
(1999). Their findings proved that Sa'adi Yusuf"s poetry was full of "linguistic units, syntactic, lexical structures and rhythmic tones" and that his poetic texts showed a "high-degree poeticism of parallelism" in addition to creative lexis. In addition, the poet's tight and artistic style of writing was best observed through parallelism. What was more, parallel structures observed in their research article reinforced the poet's mastery of language which totally reflected his ambitions and desires to introduce his readers with "newness and surprise".

In the journal article, "Aspects of Political Language and Parallelism" by Ameedi (2017), he attempted to explain the role of parallelism in political speeches which was used to emphasize aim. He adopted the concept of parallelism by De Beaugrande and Dressier (1983), Beagrande (1984), Thrall and Hibbard (1960), Cook (1995), Mantgmery et al. (2007) and McGuigan (2007). He analyzed the speech using 3 levels of parallelism syntactic parallelism, semantic parallelism and phonological parallelism. Syntactic parallelism was then sub-categorized into word level, phrase level and clause level. Semantic parallelism was analyzed under sub-categories - synonymous and antonymous parallelism whereas alliteration, assonance and rhyme were focused under phonological parallelism. The research was based on speeches by Washinton (1986), Blair (2004), Blair (2007) and Brown (2007). Descriptive qualitative method was used in approaching the use of parallelism at different linguistic levels. His findings showed that politicians intentionally used linguistic repertoire to achieve their aims and to strengthen their persuasive style of speaking. In addition, most common types of parallelism used in Ameedi (2017)'s study were syntactic, semantic, synthetic, antithetical, binary and ternary parallelism. The nature of theoretical background of present study is similar to those of previous research is that parallelism is used as a tool to analyze not only structure but also semantics of the selected material. What makes the present study significant from previous research is that two research focused on poetic writing and one on speech, but this present study attempted to figure out the use of symbolic representation through parallelism in novel. In other words, parallelism itself was originated from biblical writing (Fox, 2014) but in contrast, the selected material in present study is a novel which is written in prose style. Yet, features of parallelism 
can significantly be observed due to Dickens' witty style of writing. Similar to the research by Ameedi (2017), it was found that parallelism can be traced in

\section{METHODS}

\subsection{Research Design}

In carrying out this research, mixed method - the combination of In carrying out this research, mixed method - the combination of descriptive, qualitative, and quantitative methods - was used in analyzing the data collected from the novel. Symbol representation in the novel was first observed, described, interpreted, and analyzed through descriptive qualitative method. Next, parallelism found in illustrating symbols was identified. To strengthen the reliability and validity of data, they were quantitatively entered in SPSS dataset from which Pearson's correlation coefficients and Stepwise linear regression were generated.

This paper attempts to answer the following questions.

1) What are different types of symbols and parallelism reinforcing the illustration of symbols observed in the selected novel? prose style text and that the main function of parallelism is to reinforce the essence of message the writer or the speaker wants to convey.

2) How does parallelism highlight the illustration of symbols in the selected novel?

3) What is the correlation between the use parallelism in illustrating symbols?

4) What are predictive variables in stepwise multiple regression results for the effects of parallelism on the symbols?

\subsection{Material}

The material chosen to analyze is the novel A Tale of Two Cities by Charles Dickens. Being a historical novel, it includes symbols whose underlying meanings can be explored with reference to French Revolution. In addition, Dickens employed different types of parallelism in helping his readers decode the symbols in this novel. Although parallelism is known as rhetorical figure in ancient Near Eastern poetry and biblical prose (Berlin, 1992), significant presence of parallelism is found in selected novel. For those reasons above, 
the novel A Tale of Two Cities by Charles Dickens was chosen to analyze its symbolic representation through parallelism.

\subsection{Instruments}

Types of symbol by Pickering and Hoeper (1986) was adopted in categorizing symbols in the novel. Types of parallelism used in analyzing symbols in the novel were antithetic parallelism by Bullinger (1898), clarification parallelism by Bulkeley (2001), intensification parallelism by Bulkeley (2001), progression parallelism by Parry (2007), repetition parallelism, synonymic parallelism by Lowth (1753), synthetic parallelism by McCoy (2003) and semantic parallelism by Kosten-berger and Patterson (2011). To make data analysis as scientific as possible, Pearson's correlation

\section{RESULTS AND DISCUSSION}

It can be seen in the novel A Tale of Two Cities by Charles Dickens that it is interwoven with events in France and England before and during the French Revolution. Being a novel plotted in accordance with social, economic and most importantly political chaos, significant use of symbols can be found in most parts of coefficients and Stepwise linear regression were used.

\subsection{Data Collection and Data Analysis}

Data were collected from the novel A Tale of Two Cities by Charles Dickens. The focus was on the use of words, phrases or clauses which symbolize preparation for French Revolution, readiness to take part in revolution, tyranny, oppression, vengeance, fate, death and emotional bound. First, symbols used in the novel were observed in addition to exploring how parallelism was used in reinforcing the illustration of symbols. Data were entered in SPSS 26.0 Dataset. Correlation between variables was explored using Pearson's correlation coefficients. In addition, stepwise linear regression was used to predict the outcome of a response variable. Finally, data interpretation was conducted based on results of SPSS.

the novel. In illustrating symbols, it can be noted that the writer employs different types of parallelism to persuade the readers to keep on reading and to help them understand more about hidden meanings. The effects parallelism had on symbols can be seen in the following table. 
Table 1: Symbolic Representation Highlighted through Parallelism

\begin{tabular}{|c|c|c|c|c|c|c|c|c|c|c|c|c|c|}
\hline No. & Symbol & Type & Referent & 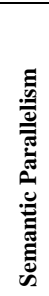 & 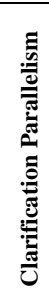 & 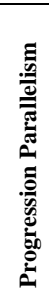 & & 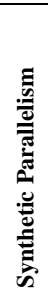 & 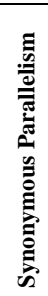 & 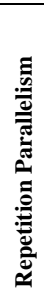 & 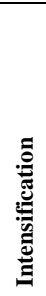 & 苞 & 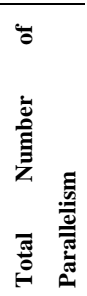 \\
\hline 1 & Rose & Private & $\begin{array}{l}\text { Readiness to } \\
\text { start } \\
\text { revolution }\end{array}$ & 3 & 0 & 1 & 2 & 1 & 0 & 0 & 0 & & 7 \\
\hline 2 & Bastille & Traditional & Oppression & 2 & 6 & 1 & 0 & 0 & 1 & 0 & 0 & & 10 \\
\hline 3 & Blue cap & Original & $\begin{array}{l}\text { Preparation for } \\
\text { revolution }\end{array}$ & 0 & 1 & 1 & 0 & 0 & 0 & 0 & 0 & & 2 \\
\hline 4 & Carmagnole & Traditional & $\begin{array}{l}\text { Readiness to } \\
\text { start } \\
\text { revolution }\end{array}$ & 3 & 2 & 0 & 0 & 0 & 0 & 1 & 1 & & 7 \\
\hline 5 & Chateau & Private & Tyranny & 9 & 4 & 3 & 4 & 0 & 0 & 3 & 2 & & 25 \\
\hline 6 & Farmer & Private & Death & 1 & 5 & & 1 & 0 & 0 & & 1 & & 8 \\
\hline 7 & Footsteps & Original & Fate & 2 & & 3 & 2 & 0 & 0 & 0 & 1 & & 8 \\
\hline 8 & Golden thread & Private & $\begin{array}{l}\text { Emotional } \\
\text { bound }\end{array}$ & 1 & 3 & 0 & 0 & 0 & 1 & 0 & 0 & & 5 \\
\hline 9 & Grindstone & Original & Death & 1 & 3 & 1 & 0 & 0 & 0 & 0 & 0 & & 5 \\
\hline 10 & Knitting & Private & $\begin{array}{l}\text { Preparation for } \\
\text { revolution }\end{array}$ & 3 & 2 & 3 & 0 & 2 & 1 & 1 & 0 & & 12 \\
\hline 11 & La Force & Traditional & Oppression & & 5 & 0 & 0 & 0 & 0 & 2 & 0 & & 7 \\
\hline 12 & La Guillotine & Traditional & Oppression & 2 & 0 & 0 & 0 & 0 & 0 & 0 & 0 & & 2 \\
\hline 13 & $\begin{array}{l}\text { Madame } \\
\text { Defarge }\end{array}$ & Private & Vengeance & 7 & 9 & 11 & 2 & 1 & 1 & 3 & 0 & & 34 \\
\hline 14 & Red cap & Original & $\begin{array}{l}\text { Readiness to } \\
\text { start } \\
\text { revolution }\end{array}$ & 5 & 3 & 3 & 0 & 0 & 2 & 0 & 1 & & 14 \\
\hline 15 & Shoes & Traditional & Fate & 0 & 1 & 1 & 0 & 0 & 0 & 4 & 0 & & 6 \\
\hline 16 & Storm & Original & $\begin{array}{l}\text { Readiness to } \\
\text { start } \\
\text { revolution }\end{array}$ & 2 & 3 & 0 & 1 & 0 & 0 & 0 & 1 & & 7 \\
\hline 17 & The Marquis & Private & Tyranny & 2 & 5 & 1 & 0 & 1 & 0 & 1 & 0 & & 10 \\
\hline
\end{tabular}

Journal of English Education Vol. 7 No. 1, June 2021

http://journal.upp.ac.id/index.php/JEE

P-ISSN:2459-9719, E-ISSN 2597-7091

DOL: https://doi.org/10.30606/jee 


\begin{tabular}{|c|c|c|c|c|c|c|c|c|c|c|c|c|}
\hline No. & Symbol & Type & Referent & 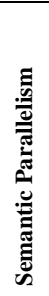 & 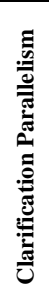 & 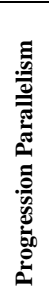 & 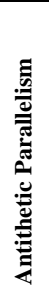 & 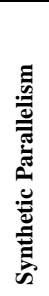 & 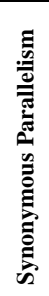 & 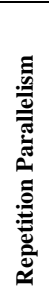 & 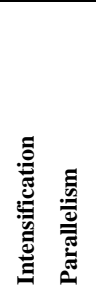 & 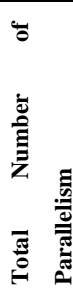 \\
\hline 18 & Wine & Traditional & Death & 10 & 10 & 0 & 0 & 0 & 0 & 1 & 2 & 23 \\
\hline \multirow[t]{2}{*}{19} & Woodman & Private & Fate & 2 & 0 & 0 & 0 & 0 & 0 & 0 & 0 & 2 \\
\hline & Total & & & 55 & 62 & 29 & 12 & 5 & 6 & 16 & 9 & 194 \\
\hline
\end{tabular}

Finding 1 (Research question 1)

What are different types of symbols and parallelism reinforcing the illustration of symbols observed in the selected novel?

With regard to Table 1 , the types of symbols found in the novel A Tale of Two Cities by Charles Dickens in order of high frequency to low frequency are private symbols, traditional symbols and original symbols. Different types of parallelism reinforcing the illustration of symbols in order of high frequency to low frequency are clarification parallelism, semantic parallelism, progression parallelism, repetition parallelism, antithetic parallelism, intensification parallelism, synonymous parallelism and synthetic parallelism.

\section{Finding 2 (Research question 2)}

\section{How does parallelism highlight the}

illustration of symbols in the selected novel?
To be specific, the most frequently used types of parallelism in depicting symbols in all three books of the novel are clarification parallelism and semantic parallelism. They were employed more frequently than other types of parallelism as clarification parallelism can help readers get additional information about the symbols, and semantic parallelism gives clues to underlying meaning behind symbols through literary devices. Among symbols, Madame Defarge was illustrated as the most frequent symbol - private symbol - that represents vengeance which is part of the theme of the novel. Chateau and wine, in addition, private symbol and traditional symbol, were also employed to reinforce the tyranny and death in the novel as it was based on French Revolution. Chateau - a symbolic representation of "tyranny" - is the second most frequent symbol found in the novel as it has been used as opposition to Madame Defarge 
who experienced traumatic childhood. Chateau and Madame Defarge were, therefore, employed as symbols to represent the rich and the poor, the tyrant and the victim, and the powerful and the powerless. This symbolic representation gives the readers the clue to Madame Defarge's vengeful character.

\section{Findings 3 (Research question 3)}

What is the correlation between the use parallelism in illustrating symbols?

According to the statistical results in SPSS, correlations between semantic parallelism and clarification parallelism, semantic parallelism and antithetic parallelism, and progression parallelism and clarification parallelism were significant at the borderline of statistical significance - at .05 $(\mathrm{p}<.05)$ whilst correlations between semantic parallelism and intensification parallelism, semantic parallelism and total number of parallelism, clarification parallelism and total number of parallelism, progression parallelism and total number of parallelism, and intensification parallelism and total number of parallelism were statistically significant at $.01 \quad(\mathrm{p}<.01) \quad$ level. Summarization of Pearson's correlations between symbolic representation and types of parallelism can be seen in Table 2 .

Table 2: Correlations between Symbolic Representation and Types of Parallelism

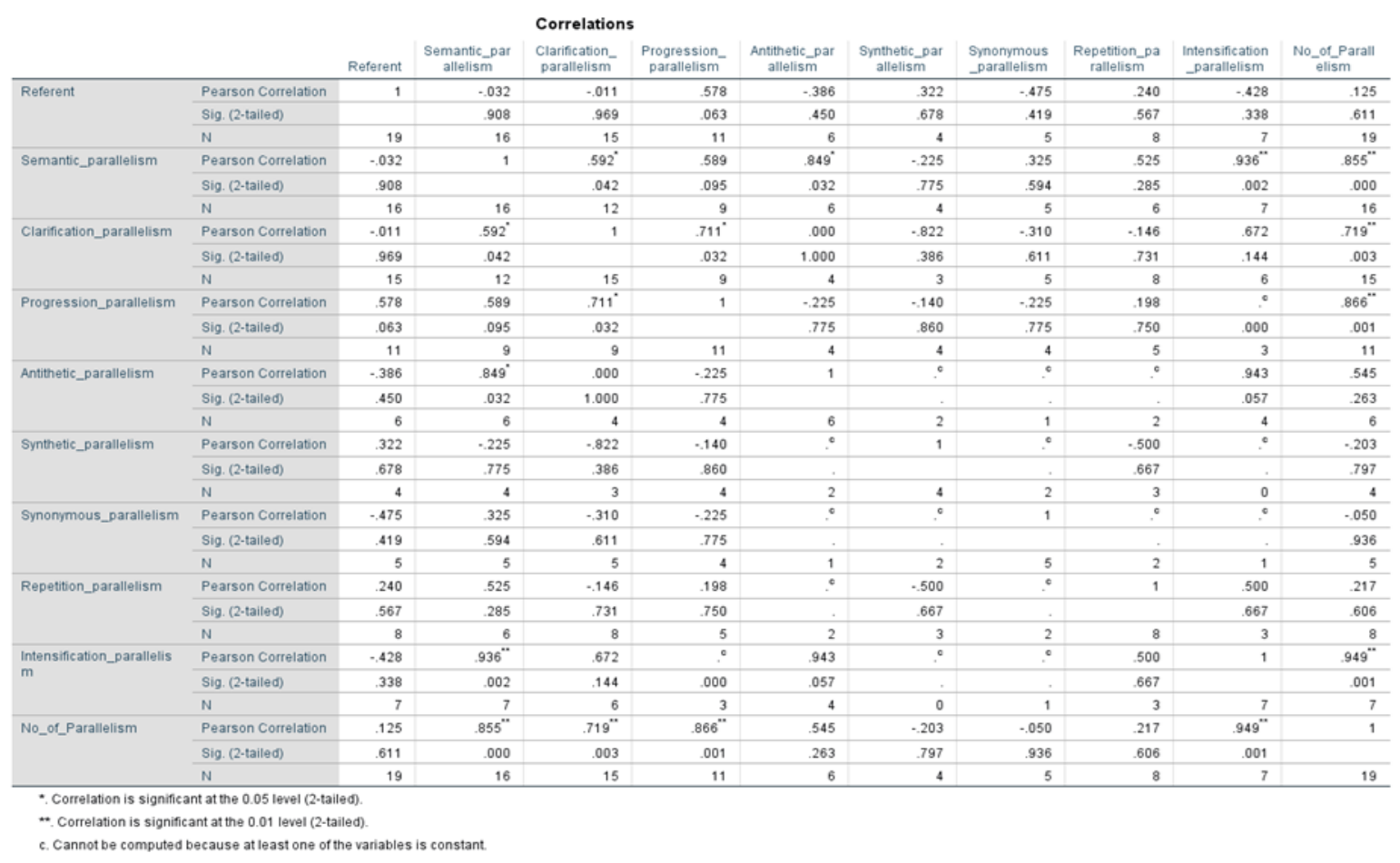

Journal of English Education Vol. 7 No. 1, June 2021

http://iournal.upp.ac.id/index.php/JEE

P-ISSN:2459-9719, E-ISSN 2597-7091

DOL: https://doi.org/10.30606/jee 
With regard to Table 2, semantic parallelism and clarification parallelism are correlated as the writer tended to employ symbol at one hand and to give clues or additional information at another hand. The reason behind this is that he attempted to make his readers think and decode as the novel progresses.

In addition, Table 2 also proves the correlation between semantic parallelism and antithetic parallelism. It can be observed that the writer introduced two opposite situations that reinforces each other. For instance, miserable scenes at La Force depict oppression whereas the Marquis implies tyranny. Besides, footstep illustrate fate or attempt for survival while red wine foreshadows death.

The correlation between progression parallelism and clarification parallelism is also significant in the novel. The action of knitting has progressed through one progressive action after another and at the same time, the writer endeavoured to give additional information about actions. The thing is, the action like knitting and approaching with echoing footsteps are purposefully included as symbols. Although original symbol like wine and footsteps can be implied by readers using their schematic knowledge, progressive actions which are used as private symbols like knitting and the woodman can be fully understood only when additional information about contextual clues is explained through clarification parallelism.

Statistically significant correlation at .01 level includes semantic parallelism and intensification parallelism at .002. It is found throughout the analysis of symbolic representation highlighted by the use of parallelism that symbols employed through semantic parallelism are rarely reinforced by intensification parallelism.

Correlation between semantic parallelism and total number of parallelisms is also statistically significant at .000 which is zero correlation. Semantic parallelism is second most frequent and therefore a slight increase or decrease in its number does not totally contribute to the total number of parallelisms. Likewise, clarification parallelism is the most frequent parallelism in the novel and 
with regard to the fact that correlation between clarification parallelism and total number of parallelism is significant at .003 level, certain changes in its number does not have great impact on total number of parallelism. Correspondingly, progression parallelism is correlated with total number of parallelisms at .001 level, which proves that there is not relationship between these two variables. Similarly, intensification parallelism and total number of parallelisms are correlated at .001 level and thus Table 2 firmly proves that they are not related.

\section{Findings 4 (Research question 4)}

What are predictive variables in stepwise multiple regression results for the effects of parallelism on the symbols?

As shown in Table 3 below, the standardized coefficients for Semantic parallelism $\quad(\beta=-.599, \quad \mathrm{p}<.05) \quad$ and Progression parallelism $\quad(\beta=1.095$, $\mathrm{p}<.05)$ are significant. The effects of these parallelism - semantic parallelism and progression parallelism - are significant and are predictive variables. In other words, a unit presence of progression parallelism increases (1.095) units in representation of referent while a unit presence of semantic parallelism decreases (-.599) units in representation of referent in the novel. This firmly proves that semantic parallelism and progression parallelism are factors that contribute to the illustration of referent.

Table 3: Stepwise Linear Regression Results for Referent Illustrated by Parallelism

\begin{tabular}{|c|c|c|c|c|c|c|}
\hline \multicolumn{7}{|c|}{ Coefficients $^{\mathrm{a}}$} \\
\hline \multirow[b]{2}{*}{ Model } & & \multicolumn{2}{|c|}{ Unstandardized Coefficients } & \multirow{2}{*}{$\begin{array}{c}\text { Standardized } \\
\text { Coefficients } \\
\text { Beta } \\
\end{array}$} & \multirow[b]{2}{*}{$\mathrm{t}$} & \multirow[b]{2}{*}{ Sig. } \\
\hline & & $\mathrm{B}$ & Std. Error & & & \\
\hline \multirow[t]{3}{*}{1} & (Constant) & 3.209 & .757 & & 4.240 & .005 \\
\hline & Semantic_parallelism & -.524 & .205 & -.599 & -2.550 & .043 \\
\hline & Progression_parallelism & .812 & .174 & 1.095 & 4.661 & .003 \\
\hline
\end{tabular}

a. Dependent Variable: Referent 


\section{Discussion}

In Pickering and Hoeper (1986)'s words, there are 3 main types of symbol employed in this novel: traditional symbol, original symbol and private symbol. Since the beginning of the novel, the writer uses spilt wine on the ground to foreshadow blood and death during the French Revolution. These traditional symbols are derived from Christianity as bread and wine mean flesh and blood of Christ.

What is more, Bastille and La Force are jails and they traditionally symbolize inequality and oppression whereas echoing footsteps can be regarded as original symbol which reflects the misfortunes and danger. Blue cap and red cap are used as original symbol as blue means before the revolution and red, near or during the revolution. The uprising of revolution and the vengeful character of Madame Defarge are reflected through the act of knitting which in fact is used to list people to be killed. As knitting patterns are fabricated by Madame Defarge and her followers, it can be regarded as private symbol.
Symbols are not only used to illustrate inanimate beings but also animate ones. Using simile, metaphor, symbolism, sarcasm, irony, symbolism, rhyme and alliteration, the writer gave detailed description of Madame Defarge's vengeance. Moreover, the use of the phrase "the day's wine to La Guillotine" at the beginning of Book 3, Chapter 15, the last chapter was used as original symbol to show that Carton had the last wine before going to the guillotine. This reminds the readers about the last supper or the final meal Jesus had with His Apostles before crucifixion.

The results of this research are similar to those of Hildebrandt (1985) in that both attempted to figure out the effects of the use of parallelism in selected materials. On the other hand, the focus of each paper is different as Hildebrandt (1985) highlighted the merits and demerits of parallelism in Hebrew poetry as a whole while the present study focused only symbolic representation highlighted through parallelism in the novel. The nature of 
chosen texts in present study and that of Khader and Kullab (2016) is similar as both used genres of literature rather than biblical text. Next, the chosen material of this present study is also different from that by Ameedi (2017) as he chose authentic speeches by politicians. Results of those research are significantly different due to the fact that the present study focused on the effects of parallelism in illustrating symbolic representation whereas

\section{CONCLUSION}

To sum up, this research paper points out the use of different types of parallelism in reinforcing the description of symbols. The most frequently used types of parallelism in depicting symbols found in the novel are semantic parallelism and clarification parallelism. The most frequent type of symbol employed in the novel is private symbol which was created by Dickens to arouse reader's interest and to make readers carried away by symbols which can be decoded through active reading. The most important of all is that symbols are used
Khader and Kullab (2016) emphasized "high-degree poeticism of parallelism" sprouted from the poet's artistic writing and Ameedi (2017) highlighted how parallelism was used by politicians in their speech to achieve their goals. Basically, in nutshell, the focus of this present study, and those of Khader and Kullab (2016) and Ameedi (2017) share the same nature in that all research attempted to figure out the style of writer or speaker.

not only to persuade readers to keep on reading but also to help them understand more about the underlying meaning behind these. In addition, they reflect the culture and tradition as well as social, economic and political situation of a particular era - before and during French Revolution - in vivid description. In short, the paper is significant in the field of parallelism and symbolic representation as it focused on a piece of literature - novel while most research on symbolic representation through parallelism were done on biblical writing, poetic 
writing and political speeches. This paper no doubt instills an interest in researchers to start exploring parallelism which is known to be significant in biblical and poetic texts in literature written in prose style. It is believed that this paper will be useful for those who are learning different types of parallelism and their effects on symbols.

\section{Acknowledgements}

First and foremost, my gratitude goes to Dr. Kyi Shwin, Rector of Yangon University of Foreign Languages and Dr. Mi Mi Aung, Pro-Rector of Yangon University of Foreign Languages, for their continuous support. Secondly, I would like to express my sincere thanks to Dr. Ni Ni Aung, Professor and Head of English Department, Yangon University of Foreign Languages for sharing her knowledge and supportive guidance. I would like to thank Sayamagyi Daw Khin Lay Myint, Retired Professor, Department of English, University of Yangon, for inspiring me with her vast knowledge of literature. Most importantly, I would also like to express my sincere gratitude to Dr. Poe Poe, Professor and Head of English Department, University of Yangon and Director of National Centre for English Language, for her kindness and guidance.

\section{REFERENCES}

Ameedi, R. A. (2017). Aspects of Political Language and Parallelism. Journal of Education and Practice, 8(34), 185-200.

Berlin, A. (1992). Parallelism. In D. N. Freedman, The Anchor Yale Bible Dictionary (pp. 154-162). New York: Doubleday.

Bhatti, R. K. (2013, December 1). Types of Parallelism. Lohore.

Bullinger, E. W. (1898). Figures of Speech Used in the Bible. (Eyre, Producer) Retrieved March 2014, from www.tentmaker.org/bullinger.htm

Burkeley, T. (2001). Literary Features. Hypertext Bible Commentary - Amos. New Zealand. Retrieved from http://www.bible.gen.nz/amos/literary/literat.htm

JEE (Journal of English Education) Vol. 6 No. 2, December 2020

http://journal.upp.ac.id/index.php/JEE

P-ISSN: 2459-9719, E-ISSN 2597-7091

DOI: https://doi.org/10.30606/jee.v6i2 
Chaffey, T. (2012). Parallelism in Hebrew Poetry Demonstrates a Major Error in the Hermeneutic of Many Old-Earth Creationists. Answers Research Journal, 5, 115-123.

Dickens, C. (1859). A Tale of Two Cities. London: Chapman \& Hall.

Fox, J. (2014). Explorations in semantic parallelism. Canberra ACT: The Australian National University.

Freeman, J. (2008, August 24). Literary and Rhetorical Devices. Retrieved July 14, 2012 , from Edublogs: http://literary.edublogs.org/

Gauding, M. (2009). The Signs and Symbols Bible: The Definitive Guide to Mysterious Markings. New York: Sterling.

Gaultney, M. (2005). The Parallel Structure of Proverbs. Harrisburg, NC, US: The Department of Biblical Studies in Candidacy.

Gilham, F. M. (2014). Psalms: Blessed is the Man.

Hildebrandt, T. A. (1985). Proverbial Poetry: Its Setting and Syntax. Bulgaria: Sheffield University Press.

Hori, M. (2004). Investigating Dickens' Style: A Collocational Analysis. NY: Palgrave MacRemillan.

Khader, Khader Tawfiq and Kullab, Mohammed Mostafa. (2016, February). The Structure of Parallelism in Sa'adi Yusuf's Poetry. International Journal on Studies in English Language and Literature (IJSELL), 4(2), 39-51.

Kondala, S. (2013). Nature of Plot in Bemba Novels: The Case of Chilangwa's Sheli Wa Ciatu, Kasonkomona's Ubuseko Mu Bulanda, and Launshi's Ukutangila Tekufika. Lusaka, Zambia: The University of Zambia.

Kostenberger, A. J. (2011). Invitation to Biblical Interpretation. Michigan: Kregel Academic and Professional.

Leech, Geoffrey and Mick Short. (2007). Style in Fiction: A Linguistic Introduction to English Fictional Prose (2nd ed.). Great Britain: Pearson Education Limited.

Literature, E. (2011). Encyclopaedia Britannica. Encyclopaedia Britannica Ultimate Reference Suite. Chicago.

Lowth, R. (1753). Lectures on the Sacred Poetry of the Hebrews. Retrieved March 2014, from http://faculty-staff.ou.edu/L/A/-Robert.RISOCOLON.html

Mahlberg, M. (2007). Clusters, key clusters and local textual functions in Dickens. Corpora.

JEE (Journal of English Education) Vol. 6 No. 2, December 2020

http://journal.upp.ac.id/index.php/JEE

P-ISSN: 2459-9719, E-ISSN 2597-7091

DOI: https://doi.org/10.30606/jee.v6i2 
Manning, E. N. (2008). Ancient Greek and Ancient Hebrew Agrarianism: An Ecocritical Study of Hesiod's Works and Days and the Book of Proverbs. Louisiana: Louisiana State University and Agricultural and Mechanical College.

McCoy, B. (2003, Fall). Chiasmus: An Important Structural Device Commonl Found in Biblical Literature. CTS Journal, 9.

Naw Ju Paw, D. (2003). Parallelism: A Literary Style of the Bible. Myanmar Arts and Science. University of Yangon .

Parry, D. W. (2007). Poetic Parallelisms in the Book of Mormon. Utah: Brigham Young University.

Patterson, R. D., \& Kostenberger, A. J. (2011). Invitation to Biblical Interpretation: Exploring the Hermeneutical Triad of History, Literature and Theology. Michigan, USA: Kregel Academic Professional.

Pickering, J. H. and Hoeper, J. D. (1986). Literature. New York: MacMillan Publishing Company.

Roberts, L. (2011). Rhetoric. (Penn State University) Retrieved March 2014, from http://faculty-staff.ou.edu/L/Lauer-1/LauersRhetoric.html 